\title{
Motor fault detection using sound signature and wavelet transform
}

\author{
Emad Awada ${ }^{1}$, Aws Al-Qaisi', Eyad Radwan ${ }^{2}$, Mutasim Nour ${ }^{3}$ \\ ${ }^{1}$ Department of Electrical Engineering, College of Engineering Technology, Al-Balqa Applied University, Amman, Jordan \\ ${ }^{2}$ Department of Electrical Engineering, Faculty of Engineering Technology, Applied Science Private University, Amman, Jordan \\ ${ }^{3}$ School of Engineering and Physical Sciences, Heriot-Watt University, Dubai, United Arab Emirates
}

\begin{tabular}{l} 
Article Info \\
\hline Article history: \\
Received Apr 28, 2021 \\
Revised Jan 24, 2022 \\
Accepted Jan 30, 2022 \\
\hline
\end{tabular}

Keywords:

Condition monitoring

Discrete wavelet transform

Fault diagnosis

Induction motor

Sound analysis

\begin{abstract}
The use of induction machines has gained fast popularity in many aspects of today's energy applications and industrial productions. However, just as with any other machine, failure is expected due to a variety of faults in component and system levels. Therefore, it is necessary to improve machine reliability by performing preventive maintenance and exploring faulty indications in advance to avoid future failures. In normal operation, a distinct machine sound signature can be identify. Therefore, at any faulty operation, diagnosis of potential error can be defined based on output signature sound data analysis. Yet, this process of monitoring induction machine sounds and vibration can be hectic and extensive in terms of collecting data and compiling analysis. That is, a huge number of data samples need to be collected and stored in order to define abnormality operation. Therefore, in this work, wavelet-based algorithms were developed as an analysis process to analyze collected data and identify abnormality, with much fewer data samples and compiling process, as special prosperity of wavelet transform. As a result, MATLAB codes were implemented to analyze data based on sound signature technique and wavelet transform algorithms to show a significant improvement in identifying potential error and abnormality conditions.
\end{abstract}

This is an open access article under the CC BY-SA license.

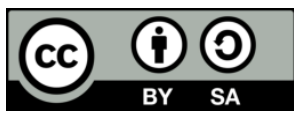

\section{Corresponding Author:}

Emad Awada

Department of Electrical Engineering, Al-Balqa Applied University

Amman, Jordan

Email: emad.awada@bau.edu.jo

\section{INTRODUCTION}

In today's large and heavy industries revolution, induction motors play an important role as driver machinery due to their affordable cost, easy maintenance, high reliability, and ease of operations. However, this is not the case all the time, since many faults may occur causing failures or even breakdown with potentially catastrophic results. Many of these faults are indistinguishable, can't be detected, and could inherent into the machine main core causing bigger issues. Therefore, faults such as broken rotor bars, winding faults, bearing failure, stator, and rotor unbalanced, and many more other faults needs to be detected and identified [1], [2]. Meanwhile, as an economic value, voltage distortion and phase imbalance costs the US somewhere between 1 to 2 billion dollars a year in failures [3].

Many researches have been done to develop a processing system of monitoring, collecting, and analyzing data required to prevent major failures. In fact, undetected small failures could potentially lead to catastrophic failures with consequences of extreme vibrations, poor performances, and high thermal stress [4], [5]. A variety of machine faults detection applications were studied by many researchers [4]-[9] to determine and diagnose faulty incidents through waveform spectral components such as voltage, current, power, 
temperature, vibrations, and sound captured during the brief operation. In most researches, digital signal processing (DSP) has been used as primary tools in the area of electrical machines faults detection analysis and advanced over the recent decades [8]-[11]. However, such detection is based on conventional DSP analysis of Fourier transform [7].

Although Fourier transform has wide usage in DSP applications, Fourier transform analysis has some shortcomings comparing to other analysis algorithms [12]. For example, in Fourier, a transformed signal from time to frequency domain may losses some critical data information. In addition, Fourier has shown a lack of ability for non-stationary signals analyzing [12], [13], as Fourier transform assumes individuality of each frequency component, gives a limitation approach.

Other researches, as in [14]-[17], have been invested in presenting their tested waveform data in methods of time-varying or nonstationary based on dilation and translation of a signal to provide dynamic time and frequency localization adjustable windows (scaling concept to fit multi-frequency components). However, in this work, a unique special feature of the wavelet transform algorithm will be used to deliver a combined framework for advanced signals processing analysis application with much fewer data samples and shorter testing time [18], [19] for stationary and non-stationary motor output sounds waveform.

As a result, discrete wavelet transform (DWT) will be presented as a new method of detecting machine failure based on faulty noise indication to identify fault potential that may lead to machine malfunctions. The distinctive of this new proposed DWT algorithm will allow analyzing machine output sounds with fewer data samples as compared to fast Fourier transform (FFT) by the unique property of decomposition and de-noising filters to isolate faulty frequencies and locate abnormality faster and in early stages.

\section{SIGNAL TO NOISE RATIO}

The signal-to-noise ratio (SNR) is a regularly used process to evaluate the quality of a signal and estimate the influence of noise on a signal. In this process, the power ratio of the signal power to the total noise is estimated by the spectral data [20], [21]. In fast Fourier transform (FFT), the captured waveform data samples will be transformed into the frequency domain where the captured signal will be in the form as shown in (1).

$$
x_{\text {out }}(n)=s(n)+\gamma(n)
$$

Where $s(n)$ is the signal and $\gamma(n)$ is the noise.

For optimal accuracy, $x_{\text {out }}(n)$ will consist of $\mu$ number of samples and an integer number sine-wave whole cycles [6]. Therefore compute SNR, $x_{\text {out }}(h)$, with $\mu$-point FFT of $x_{\text {out }}(n)$, will be calculated as given by (2).

$$
x_{\text {out }}(h)=\sum_{n=0}^{\mu-1} x_{\text {out }}(n) e^{-j(2 \pi / \mu) h n}
$$

With frequency component $\omega$ in the $j$-th element of $x_{\text {out }}(h)$, Parseval's theorem for FFT [19], the estimation of the variance of the signal $s(n)$ (which is also the signal power $\hat{p}_{s}$ ) as given in (3).

$$
\hat{p}_{s}=\frac{2}{(\mu-1) \mu}|x(j)|^{2}
$$

However, unbiased noise power $\hat{P}_{\eta}$ can be given by (4).

$$
\hat{p}_{n}=\frac{2}{(\mu-1) \mu} \sum_{h=1}^{(\mu-1) / 2}|x(h)|^{2} \text { and } \quad h \neq j
$$

As a result, the combination of both (3) and (4) yields SNR for frequency $\omega$ as in (5).

$$
S N R=10 \log _{10}\left[\frac{|x(j)|^{2}}{\sum_{h=1}^{(\mu-1) / 2} x(h)^{2}}\right] \text { and } h \neq j
$$

\section{WAVELET TRANSFORM}

While Fourier transform signal analysis is done based on one window analysis fit all frequencies, wavelet transforms provide an adjustable window analysis for different frequencies to provide good resolution in the time domain for a high-frequency component of the signal and good resolution in frequency for 
low-frequency component of the signal [22], [23]. As a result, an automatic analysis window of wavelet transform is done through the shifting and scaling process based on mother wavelet form [5]. In continuous wavelet transform, the original signal multiplied by scaling and shifting algorithm of a wavelet to be summed over time and produces low-pass and hi-pass coefficients as in (6).

$$
\Psi_{a, b}(t)=\int_{-\infty}^{\infty} f(t) \phi_{a, b}(t) d t
$$

Where

$$
\phi_{a, b}(t)=\frac{1}{\sqrt{a}} \phi \frac{t-b}{a} \text { and } a>0
$$

( $\mathrm{a}$ and $\mathrm{b}$ are dilation and translation parameters and $\sqrt{a}$ normalization factor).

Meanwhile, in DWT, convolutions with a quadratic mirror filter are performed for the decomposition process of the original signal. As a result, a predetermined filters bank of low and high-passes used to transfer raw data of the original signal into orthonormal wavelet basis or decomposing the signal by a set of independent frequency bands to remove half of the frequency spectrum at each decomposition levels without risking the signal information components [24]-[26]. DWT would have the advantage of processing and analyzing stationary signals and non-stationary signals over the FFT [27]. That is, a discrete signal X[n] decomposition can be presented as in (7).

$$
x[n]=\sum_{k} a_{j o, k} \phi_{j o, k}[n]+\sum_{j=j}^{j-1} \sum d_{j, k} \varphi_{j, k}[n]
$$

Where:

$x[n]$ is discrete signal

$\phi_{j o, k}[n]$ is scaling function

$\varphi_{j, k}[n]$ mother wavelet at scaling function

$a_{j o, k}$ approximation coefficients at scaling function

$d_{j, k}$ detail coefficients at scaling function

By applying DWT filter bank of high-pass and low-pass algorithms, detail coefficients are passed through the high-pass filter $\mathrm{h}[\mathrm{n}]$ and approximation coefficients are transferred through a low-pass filter $\mathrm{g}[\mathrm{n}]$ followed by a down-sampling by two driven by mother wavelet and the scaling function [20], [21], [28], as shown in Figure 1, which makes DWT suitable for signal analysis with fewer data samples and particularly for transient signals. However, in this work, instantaneous amplitude measurements and waveform dynamic range will be based on the low-pass approximation coefficients to eliminate noises and obtain an accurate reading.

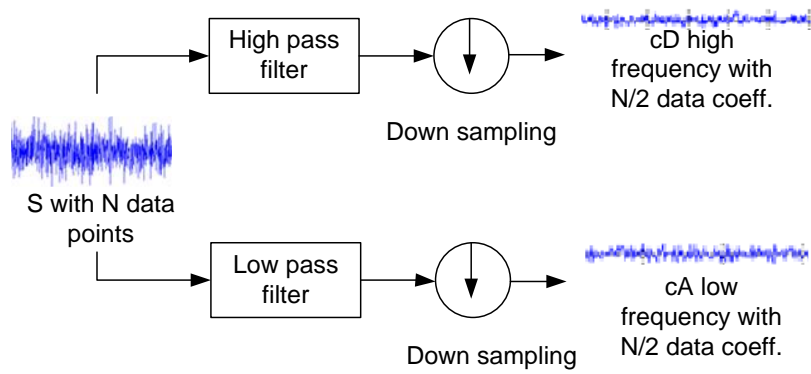

Figure 1. Wavelet transforms decomposition

\section{MOTOR FAULTS TYPES AND FAULT DIAGNOSIS}

Faults in induction motors can be classified based on fault location. With three major parts of induction motors (stator, rotor, and shaft bearing) as in Figure 2, the stator of an induction motor may cause some problems due to internal wiring and shielding problems such as open or short winding, abnormal winding connection, or ground faults. Rotor problems can be referred to as rotor internal winding and shielding (open or short winding), or mechanical bearing faults [9], [29]. In addition, induction motor failure can be caused by other mechanical parts such as bearing and an imbalanced shaft. Therefore, it is necessary to identify any potential failure. 


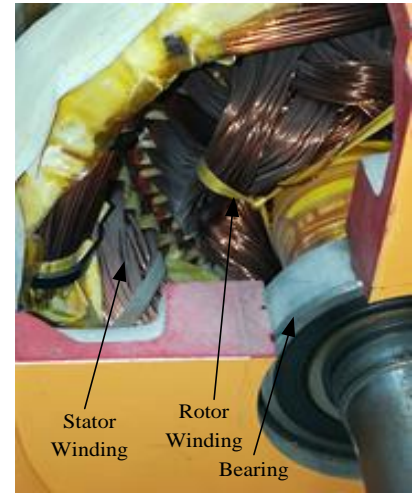

Figure 2. Induction motor stator winding, rotor winding, and bearing

Fault detection and condition monitoring of induction motor can be performed in many techniques such as sound signature analysis, vibration analysis, acoustic emission analysis, motor current signature analysis, temperature monitoring, and many other techniques [9], [17], [30]. In this work, sound signature analysis will be used to define any potential failure or potential error that may lead to a failure. As it's known, the sound is mechanical wave vibration of a medium (solid, gas, liquid) that propagate and transfer at pressure rate change known as frequency, and the differences among the level of pressure characterize amplitude.

By converting such pressure and amplitude into electrical signals, a discrete wavelet decomposition process can be applied in two levels to obtain approximation coefficients data. For example, using Haar wavelet decomposition process for the first level as in (8) if the digitized signal assumed to be $z(n)$.

$$
\left[\begin{array}{cccccc}
\frac{\sqrt{2}}{2} & \frac{\sqrt{2}}{2} & & & & \\
\frac{\sqrt{2}}{2} & -\frac{\sqrt{2}}{2} & & & & \\
& & \frac{\sqrt{2}}{2} & \frac{\sqrt{2}}{2} & & \\
& & \frac{\sqrt{2}}{2} & -\frac{\sqrt{2}}{2} & & \\
& & & & \ddots & \\
& & & & & \ddots
\end{array}\right] \cdot z(n)=\left[\begin{array}{c}
\frac{\sqrt{2}}{2} z(1) \\
-\frac{\sqrt{2}}{2}(1) \\
\frac{\sqrt{2}}{2} z(2) \\
-\frac{\sqrt{2}}{2} z(2) \\
\vdots \\
\vdots
\end{array}\right]
$$

For the second level decomposition, waveform will be filtered as in (9).

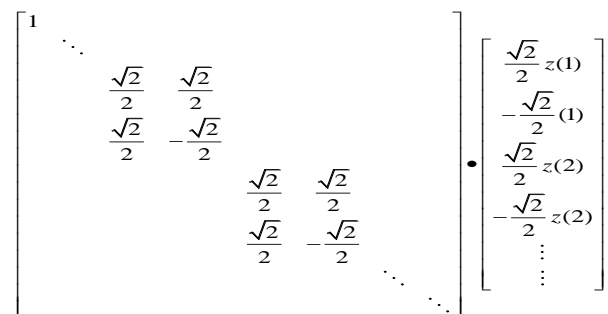

As a result, detection of sound changes can be determined through waveform amplitude voltage change and dynamic range increases (ratio of the largest and smallest component of a signal that can be measured expressed in dB [21]). DR can be given by (10).

$$
\text { Dynamic Range in } d B=20 * \log 10(\operatorname{Vmax} / V \min )
$$

As mechanical faults such as bearing faults or unbalance faults, or electrical faults such as stator or rotor winding faults may occur, unique sound changes in frequency amplitude can be defined by the frequency spectrum, which indicates a faulty or potential fault operation. However, in this work, due to the large number of samples collected and processed by FFT to obtain frequency spectrum, wavelet decomposition will be used to decrease the number of processed and stored data samples [12], [18], [24]. As shown in Figure 3 (flowchart), a continuous monitoring sequence and data acquisition as iterative MATLAB code will be performed on induction motor to collect sounds waveform data samples, apply DWT filtration and amplification to eliminate noise and analyze for abnormality. 


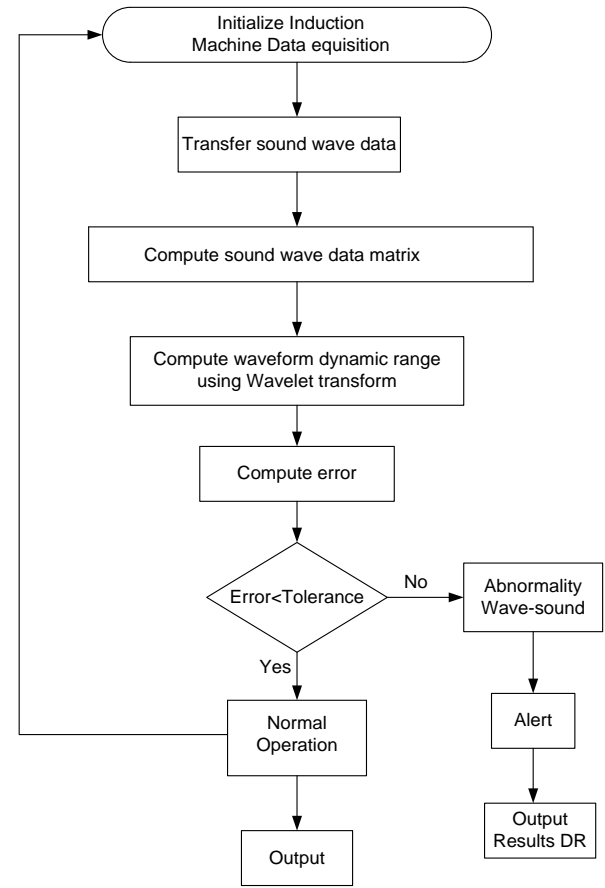

Figure 3. Flowchart sequence of iterative MATLAB codes

\section{SIMULATION and RESULTS DISCUSSION}

Sounds analysis of rotating machines can give a major indication of motor condition. By constantly monitoring and analyzing the sound behavior of a machine, as shown in Figure 4, the decision can be made on the status of the machine. For example, distress of machinery may very often reveal itself in sounds and vibration outside the normal pattern and the dynamic range of the expected waveform. In addition, shortage between rotor or stator winding due to insulation damages may lead to current flow between shorted winding and sparks based on the amount of current flow, and the ionization may result in sparks. Therefore sounds analysis of motor output sound could be a powerful tool for monitoring, detecting, comparing, and diagnosis faults due to added failure noises and allow troubleshooting in most machines.

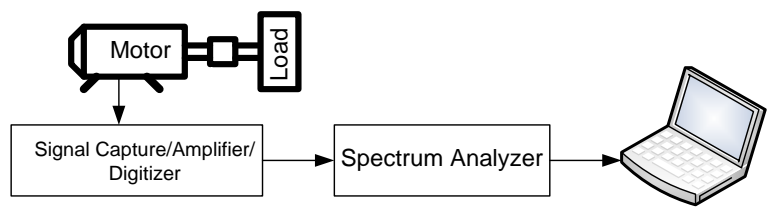

Figure 4. Sound monitoring system

In this work, a clean consistent sinusoidal waveform has been simulated as motor sound without additive error is ordered to implement a conventional testing analysis of FFT and new wavelet transform analysis. The test was intended to show the abilities of both FFT and DWT testing analysis in processing, de-noising, and explores waveform data. As noticed in Figure 5, the FFT power spectrum has specified the fundamental frequency without data decomposition or showing any other critical waveform components. While, in Figure 6, DWT has performed a de-noising and decomposition process to reveal data components of waveform characteristics in terms of amplitude and dynamic range changes.

Meanwhile, by adding abnormality to the fundamental signal as a source of potential motor failure, the new output sound waveform was analyzed and the process by both testing algorithms to define the amplitude and standpoint of the potential failure. In Figures 7 and 8, as it shows the noisy output motor sound, the FFT algorithm was used to obtain the power spectrum and define unwanted data attached to the waveform.

However, it was noticed that the noises component was closer to the noise floor and the amplitude of fundamental frequency was very high to define the magnitude of amplitude changes or any significant dynamic 
range alteration. Meanwhile, in Figure 9, the same output waveform was analyzed by DWT to perform a denoising and decomposition process. In this algorithm, DWT was able to pinpoint and represent changes (distortion) that occur within the waveform with one-fourth number of data samples. That is, the amplitude change was clearly defined and dynamic range alteration was determined based on the changes of the highest and lowest waveform amplitude of the approximation decomposition cA with much fewer data samples and time to compile.

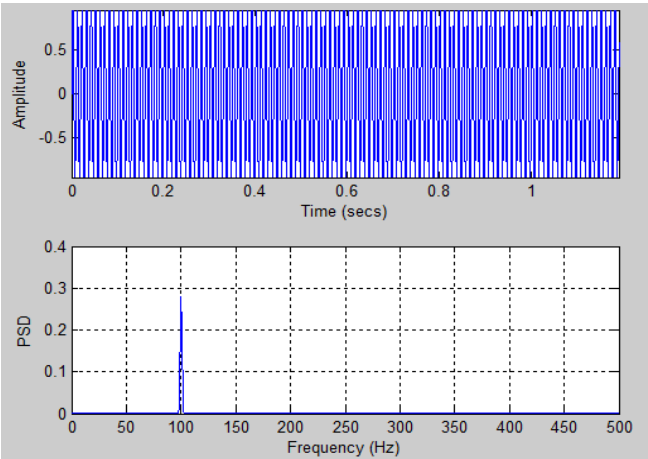

Figure 5. Original clean waveform and power representation of frequency domain

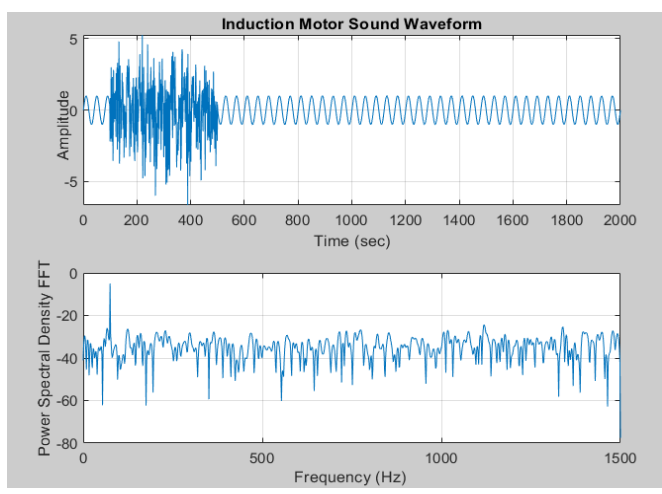

Figure 7. Faulty waveform and power spectrum representation of frequency domain

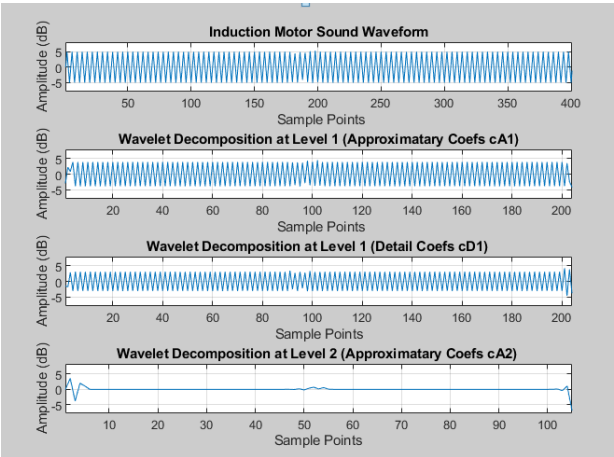

Figure 6. Original clean waveform and discrete. wavelet analysis

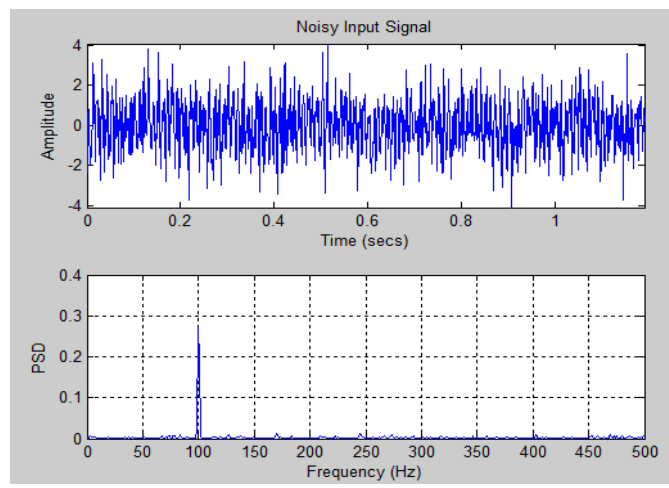

Figure 8. Original faulty waveform and power spectrum representation of frequency domain

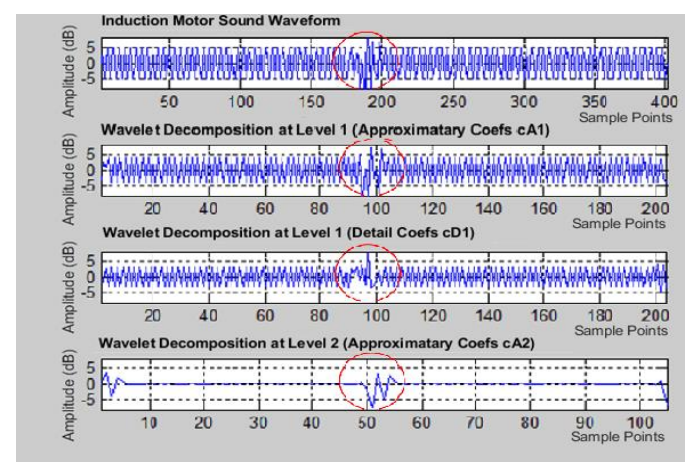

Figure 9. Waveform distortion based on wavelet analysis

By obtaining the maximum and the minimum deconstruct waveform amplitude, the dynamic range was computed based on different types of mother wavelet. For a clean motor waveform with no failure, Tables 1 and 2 show the instantaneous dynamic range of normal operation for both no-load and with load 
status. Meanwhile, Tables 3 and 4 show an instantaneous dynamic range for faulty waveform for both no-load and with load respectively.

This test was based on two different algorithms. For FFT, signal to noise ratio was used to determine the level of noise due to failure occurrence measured in $\mathrm{dB}$. Meanwhile, wavelet transforms algorithms were used based on waveform dynamic range calculation to determine failure occurrence. Based on results shown in Tables 1 to 4 and Figures 10 (a) and 10 (b), it was clear that wavelet transforms algorithms significant results by using Daubechies (dbn) wavelet at the second level of waveform decomposition

Table 1. No load no error

\begin{tabular}{ccccc}
\hline Wavelet & $\mathrm{db} 4$ & $\mathrm{db} 12$ & Haar & FFT/dB \\
\hline $\mathrm{cA} 1$ & 0.63 & 0.68 & 0.42 & 0.97 \\
$\mathrm{cA} 2$ & 0.25 & 0.29 & 0.22 & 0.97 \\
\hline
\end{tabular}

Table 3. No load with error

\begin{tabular}{ccccc}
\hline Wavelet & $\mathrm{db} 4$ & $\mathrm{db} 12$ & Haar & FFT/dB \\
\hline $\mathrm{cA} 1$ & 0.86 & 0.81 & 0.62 & 0.89 \\
$\mathrm{cA} 2$ & 0.65 & 0.62 & 0.53 & 0.89 \\
\hline
\end{tabular}

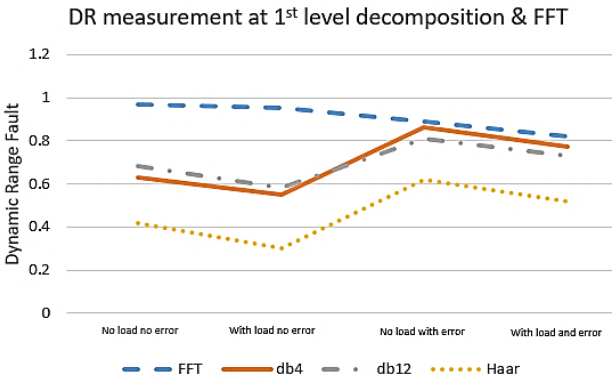

(a)
Table 2. With load no error

\begin{tabular}{ccccc}
\hline Wavelet & $\mathrm{db} 4$ & $\mathrm{db} 12$ & Haar & FFT/dB \\
\hline $\mathrm{cA} 1$ & 0.55 & 0.58 & 0.30 & 0.95 \\
$\mathrm{cA} 2$ & 0.16 & 0.20 & 0.17 & 0.95 \\
\hline
\end{tabular}

Table 4. With load and error

\begin{tabular}{ccccc}
\hline Wavelet & $\mathrm{db} 4$ & $\mathrm{db} 12$ & Haar & FFT/dB \\
\hline $\mathrm{cA} 1$ & 0.77 & 0.73 & 0.52 & 0.82 \\
$\mathrm{cA} 2$ & 0.51 & 0.59 & 0.44 & 0.82 \\
\hline
\end{tabular}

DR measurement at $2^{\text {nd }}$ level decomposition \& FFT

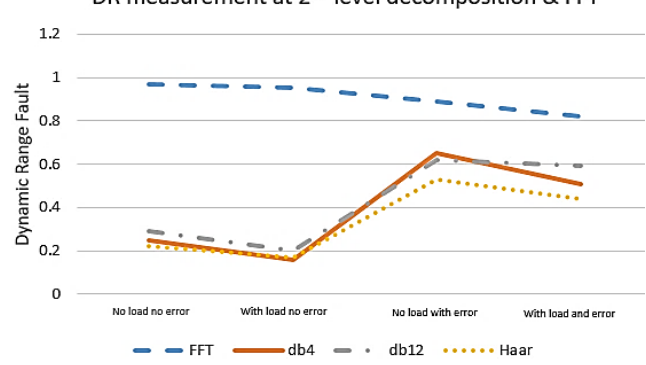

(b)

Figure 10. Motor failure detection based on dynamic range calculation for (a) instantaneous DR measurement at $1^{\text {st }}$ level decomposition and (b) instantaneous DR measurement at $2^{\text {nd }}$ level decomposition

\section{CONCLUSION}

In this work, the properties of DWT decomposition and de-noising were implemented as advanced signal processing techniques to monitor the behavior of electrical motor. Fault diagnosis of induction motors was based on the algorithms of Fourier transformations for SNR fault indication technique and wavelet transform for DR indications where used. Hence, even though the two techniques were different in compiling samples method and testing result, DWT has shown promising results in detecting faulty sounds with mush less data to compile. That is, by comparing results in terms of number of collected data samples, Fourier transformation did not show sufficient results in term of SNR (due to large number of collected data sample in power spectrum), while, wavelet transform had shown promising results in terms of computing DR and spotting deviation of motor error. In addition, based on wavelet decomposition coeffients, Daubechies wavelet has shown superior results in term of motor error detection in both 1st and 2nd level decomposition.

\section{REFERENCES}

[1] S. Singh, A. Kumar, and N. Kumar, "Motor current signature analysis for bearing fault detection in mechanical systems," Procedia Materials Science, vol. 6, pp. 171-177, 2014, doi: 10.1016/j.mspro.2014.07.021.

[2] A. Alawady, M. Yousof, N. Azis, and M. Talib, "Frequency response analysis technique for induction motor short circuit faults detection," International Journal of Power Electronics and Drive Systems (IJPEDS), vol. 11, no. 13, pp. 1653-1659, 2020, doi: 10.11591/ijpeds.v11.i3.pp1653-1659.

[3] S. B. Singh, A. K. Singh, and P. Thakur, "Accurate steady-state performance assessment of three-phase induction motor using NEMA definition," 2014 16th International Conference on Harmonics and Quality of Power (ICHQP), 2014, pp. 880-884, doi: 10.1109/ICHQP.2014.6842803.

[4] G. Didier, E. Ternisien, O. Caspary, and H. Razik, "Fault detection of broken rotor bars in induction motor using a global fault index," in IEEE Transactions on Industry Applications, vol. 42, no. 1, pp. 79-88, 2006, doi: 10.1109/TIA.2005.861368.

[5] R. Yothi, H. Tejas, K. Uma, and R. Jayapal, "Machine learning based multi class fault diagnosis tool for voltage source inverter driven induction motor," International Journal of Power Electronics and Drive Systems (IJPEDS), vol. 12, no. 2, pp. 1205-1215, 2021, doi: 10.11591/ijpeds.v12.i2.pp1205-1215. 
[6] P. Jayaswal, A. Wadhwani, and K. B. Mulchandani, "Machine fault signature analysis," International Journal of Rotating Machinery, vol. 2008, no.1, pp.1-10, 2008, doi: 10.1155/2008/583982.

[7] M. A. Al-Yoonus, and O. Sh. Y. Alyozbak, "Detection of internal and external faults of single-phase induction motor using current signature," International Journal of Electrical and Computer Engineering (IJECE), vol. 11, pp. 2830-2841, 2021, doi: 10.11591/ijece.v11i4.pp2830-2841.

[8] P. S. Barendse, B. Herndler, M. A. Khan, and P. Pillay, "The application of wavelets for the detection of inter-turn faults in induction machines," 2009 IEEE International Electric Machines and Drives Conference, 2009, pp. 1401-1407, doi: 10.1109/IEMDC.2009.5075386

[9] S. Nandi, H. A. Toliyat, and X. Li, "Condition monitoring and fault diagnosis of electrical motors-a review," in IEEE Transactions on Energy Conversion, vol. 20, no. 4, pp. 719-729, Dec. 2005, doi: 10.1109/TEC.2005.847955.

[10] P. Sharma and N. Saraswat, "Diagnosis of motor faults using sound signature analysis," International Journal of Innovative Research in Electrical, vol. 3, no. 5, pp.80-83, 2015, doi: 10.17148/IJIREEICE.2015.3524

[11] J. Pons-Llinares, V. Climente-Alarcón, F. Vedreño-Santos, J. Antonino-Daviu, and M. Riera-Guasp, "Electric machines diagnosis techniques via transient current analysis," IECON 2012 - 38th Annual Conference on IEEE Industrial Electronics Society, 2012, pp. 3893-3900, doi: 10.1109/IECON.2012.6389270.

[12] S. H. Kia, H. Henao, and G. Capolino, "Efficient digital signal processing techniques for induction machines fault diagnosis," 2013 IEEE Workshop on Electrical Machines Design, Control and Diagnosis (WEMDCD), 2013, pp. 232-246, doi: 10.1109/WEMDCD.2013.6525183.

[13] N. Dudhe and D. Waghmare, "Application of wavelet transform in power system analysis and protection," International Journal of Engineering Research \& Technology (IJERT), vol. 6, no. 5, pp. 889-892, 2017, doi: 10.17577/IJERTV6IS050511.

[14] H. Bae, Y. Kim, S. Kim, S. Lee, and B. Wang, "Fault detection of induction motors using fourier and wavelet analysis," Journal of Advanced Computational Intelligence and Intelligent Informatics, vol. 8, pp. 431-436, 2004, doi: 10.20965/jaciii.2004.p0431.

[15] R. Kechida and A. Menacer, "DWT wavelet transform for the rotor bars faults detection in induction motor," 2011 2nd International Conference on Electric Power and Energy Conversion Systems (EPECS), 2011, pp. 1-5, doi: 10.1109/EPECS.2011.6126825.

[16] J. Chen, J. Pan, Z. Li, and X. Chen, "Generator bearing fault diagnosis for wind turbine via empirical wavelet transform using measured vibration signals," Renewable Energy, vol. 89, pp. 80-92. 2016, doi: 10.1016/j.renene.2015.12.010.

[17] W. Teng, X. Ding, X. Zhang, Y. Liu, and Z. Ma, "Multi-fault detection and failure analysis of wind turbine gearbox using complex wavelet transform," Renewable Energy, vol. 93, pp. 591-598, 2016, doi: 10.1016/j.renene.2016.03.025.

[18] J. Roura and L. Romeral, "Transient analysis and motor fault detection using the wavelet transform," Discrete Wavelet TransformsTheory and Applications, pp. 19-61, 2011, doi: 10.5772/15377.

[19] E. Awada, "Hilbert based testing of ADC differential non-linearity using wavelet transform algorithms," International Journal of Electrical and Computer Engineering (IJECE), vol 8, no. 6, pp. 5071-5079, 2018, doi: 10.11591/ijece.v8i6.pp5071-5079.

[20] A. Menacer, R. Kechida, G. Champenois, and S. Tnani, "Application of the fourier and the wavelet transform for the fault detection in induction motors at the startup electromagnetic torque," 8th IEEE Symposium on Diagnostics for Electrical Machines, Power Electronics \& Drives, 2011, pp. 664-668, doi: 10.1109/DEMPED.2011.6063695

[21] H. Li, Y. Hu, and S. Wang, "Signal Detection Based on Power-Spectrum Sub-Band Energy Ratio," Electronics MDPI, vol. 10, pp. 1-26, Dec. 2020, doi: 10.3390/electronics10010064.

[22] E. Awada, "The algorithm of testing ADC effective number of bits based on hilbert and wavelet transform," 3rd International Conference on Information System and Data Mining (ICISDM), Apr. 2019, pp. 196-200. doi: 10.1145/3325917.3325921.

[23] Y. Hsueh, V. Ittangihal, W. Wu, H. Chang, and C. Kuo, "Fault diagnosis system for induction motors by CNN using empirical wavelet transform," Symmetry MDPI, vol. 11, pp. 1-15, Sep. 2019, doi: 10.3390/sym11101212.

[24] I. Daubechies, "The wavelet transform, time-frequency localization and signal analysis," IEEE Transactions on Information Theory, vol. 36, no. 5, pp. 961-1005, Sept. 1990, doi: 10.1109/18.57199.

[25] E. Awada and C. Akujuobi, "ADC testing algorithm for ENOB by wavelet transform using lab view measurements and MATLAB simulations," Journal of Engineering and Applied Sciences, vol. 13, no. 2, pp. 398-405, 2018, doi: 10.3923/jeasci.2018.398.405.

[26] K. Jayakumar and S. Thangave, "Vibration analysis of industrial drive for broken bearing detection using probabilistic wavelet neural network," International Journal of Power Electronics and Drive System (IJPEDS), vol. 5, no. 4, pp. 541-551, 2015, doi: 10.11591/ijpeds.v5.i4.pp541-551.

[27] S. Moosavi1, H. Akbari, and S. Valipour, "An open-circuit fault detection method with wavelet transform in IGBT-based DC/AC inverter used in electric vehicles," International Journal of Power Electronics and Drive System (IJPEDS), vol. 9, no. 3, pp. 12401250, 2018, doi: 10.11591/ijpeds.v9.i3.pp1240-1250.

[28] E. Awada, "The application wavelet transform algorithm in testing ADC effective number of bits," International Journal of Computer Science \& Information Technology (IJCSIT), vol. 5, no. 5, pp. 161-169, 2013, doi: 10.5121/ijcsit.2013.5512.

[29] E. Awada and M. Alomari, "Application of wavelet transform analysis to ADCs harmonics distortion," Computer and Information Science, vol. 6, no. 6, pp. 118-124, 2013, doi: 10.5539/cis.v6n3p118.

[30] R. Patel and V. Giri, "Feature selection and classification of mechanical fault of an induction motor using random forest classifier," Perspectives in Science, vol. 8, pp. 334-337, 2016, doi: 10.1016/j.pisc.2016.04.068.

\section{BIOGRAPHIES OF AUTHORS}

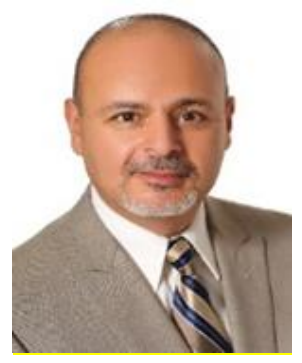

Emad Awada (iD 8. SC $\mathrm{P}$ is an associate professor received his B.S. in Electrical Engineering from Prairie View Texas A\&M University (PVAMU) in 1998. He also, received his M.S. and Ph.D. in Electrical Engineering, PVAMU 2006 and 2011 respectively. His work experiences were in the field of electrical power, energy, and signal processing. His research interests are in the areas of Power System, Renewable Energy, Energy Conservation, Mixed Signals Systems, Signal Processing, and Power Fault Detection. Currently, he is a fulltime at Al-Balqa Applied University, Electrical Engineering Department. He can be contacted at email: emad.awada@bau.edu.jo. 


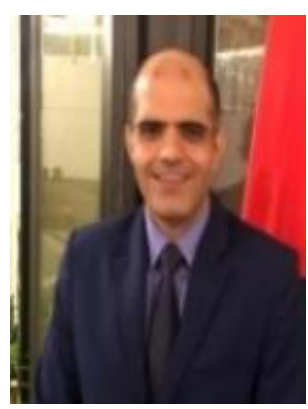

Aws Al-Qaisi (D) 8d SC P is an associate professor in Electrical Engineering Department, Al-Balqa Applied University, Jordan and member of IEEE executive committee in Jordan. $\mathrm{He}$ received his $\mathrm{PhD}$ and MSc in communication and signal processing from Newcastle university in 2006 and 2010 respectively. His research interest is Digital signal processing, Feature Extraction, Wireless communication, Digital communication. He can be contacted at email: aws.alqaisi@bau.edu.jo.

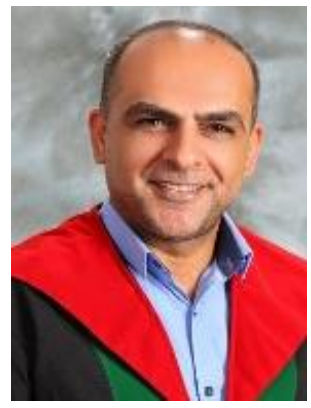

Eyad Radwan (iD IS SC P completed his BSc. from JUST in 1996, MSc. and PhD. from UPM (Malaysia) in 1999 and 2004 respectively. From 1999 till 2011 he was with UCSI University and served as the Dean of the faculty of Engineering \& built environment from 2007 to 2009, and as Chief Operating Officer from 2009 to 2011. He joined the dept. of Electrical Engineering at the Applied Science Private University, Jordan in 2012. His specialization is in the area of Electrical power, Drives and Control. He can be contacted at email: e_redwan@asu.edu.jo.

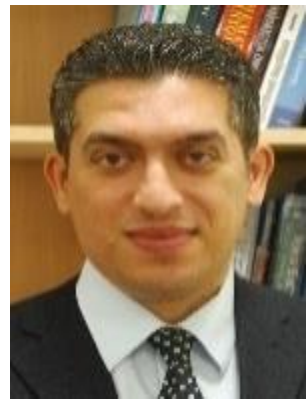

Mutasim Nour (D) 8d SC P is the Associate Director of External Relations and Industry Engagement in the School of Engineering and Physical Sciences at Dubai Campus and a member of IEEE and JEA. He is also the Director of studies for MSc Energy and Renewable Energy Engineering programmers at Dubai Campus. Prior to joining Heriot-Watt University, Dr Nour was an Associate Professor at the University of Nottingham Malaysia Campus. He can be contacted at email: mutasim.nour@hw.ac.uk. 